SEC̄̃O TEMÁTICA:

EDUCAÇÃO MATEMÁTICA

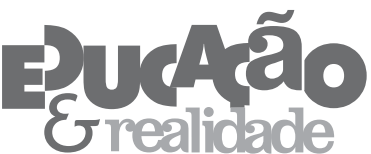

\title{
Saberes Matemáticos para a Formação de Normalistas em Sergipe (1890 - 1930)
}

Ivanete Batista dos Santos'

'Universidade Federal de Sergipe (UFS), São Cristóvão/SE - Brasil

RESUMO - Saberes Matemáticos para a Formação de Normalistas em Sergipe (1890 - 1930). Neste trabalho, é apresentado o resultado de uma pesquisa que teve por objetivo caracterizar os saberes matemáticos presentes na formação das normalistas sergipanas do Instituto de Educação Rui Barbosa (IERB) no período de 1890 a 1930. Para alcançar tal propósito, foram examinadas fontes como: decretos, regulamentos da instrução pública sergipana e programas do curso normal. Para o exame das fontes, foram utilizados entendimentos apresentados por Valente, Bertini e Morais (2017), Valente (2018), Valente (2019), em relação aos saberes profissionais dos professores que ensinam matemática. A partir do exame das fontes, é possível afirmar que o saber profissional das normalistas estava mais centrado em uma matemática a ensinar, uma vez que a matemática para ensinar só foi possível ser identificada de forma implícita.

Palavras-chave: Saberes Matemáticos. Normalista. Saber Profissional.

ABSTRACT - Mathematical Knowledge for Normalists' Formation in Sergipe $(1890$ - 1930). In this work, the result of a research that aimed to characterize the mathematical knowledge present in the Sergipe normalists' formation at Instituto de Educação Rui Barbosa (IERB) in the period from 1890 to 1930 is presented. To achieve this purpose, sources such as decrees, regulations of public education in Sergipe and programs of the normal course were examined. To examine the sources, understandings presented by Valente, Bertini and Morais (2017), Valente (2018), Valente (2019) were used in relation to the professional knowledge of teachers who teach mathematics. Based on an examination of the sources, it is possible to affirm that the professional knowledge of the teachers was more centered on a mathematics to teach, since the mathematics for teaching was only possible to be identified implicitly.

Keywords: Mathematical Knowledge. Normalist. Professional Knowledge.

Educação \& Realidade, Porto Alegre, v. 46, n. 2, e112138, 2021.

http://dx.doi.org/10.1590/2175-6236112138 
Saberes Matemáticos para a Formação de Normalistas em Sergipe (1890 - 1930)

\section{Considerações Iniciais}

Quais são os saberes matemáticos presentes na formação de normalistas sergipanas no período de 1890 a 1930 ? Os saberes identificados podem ser classificados como um saber a ensinar ou como um saber para ensinar? Ou ainda, os saberes matemáticos identificados podem ser caracterizados como um saber profissional das normalistas? Para responder a essas indagações foi definido como objetivo caracterizar os saberes matemáticos presentes na formação das normalistas sergipanas do Instituto de Educação Rui Barbosa (IERB) no período de 1890 a 1930.

A escolha da temática é justificada por dois motivos. O primeiro motivo foi instigado pela realização de um evento: o $1^{\circ}$ Seminário $\mathrm{Na}$ cional sobre Práticas Escolares e Saberes Matemáticos nas Escolas Normais $^{l}$. A partir do que está posto no título, fica claro a definição do lócus da pesquisa, o Instituto de Educação Rui Barbosa (IERB), que, durante muito tempo, formou as normalistas, ou seja, as professoras para o ensino primário.

O segundo motivo, também provocado pela proposta do evento, foi a busca por uma compreensão sobre saberes matemáticos, e para isso foi fundamental uma aproximação com investigações e sistematizações desenvolvidas por pesquisadores vinculados ao Grupo de Pesquisa de História da Educação Matemática no Brasil (GHEMAT - Brasil) em títulos como: Novos aportes teórico -metodológicos sobre saberes profissionais na formação de professores que ensinam Matemática (Valente; Bertini; Morais, 2017), O saber profissional do professor que ensina Matemática: o futuro do passado (Valente, 2018) e Programas de ensino e manuais escolares como fontes para estudo da constituição da Matemática para ensinar (Valente, 2019). Nestes textos, os pesquisadores apresentam um entendimento sobre o saber profissional do professor que ensina matemática a partir de pesquisas desenvolvidas pelos membros da Equipe de Pesquisa de História Social da Educação - ERHISE da Universidade de Genebra.

De pronto vale ressaltar que foram identificadas pesquisas que já examinaram aspectos relacionados à formação das normalistas em Sergipe a partir do Instituto de Educação Rui Barbosa (IERB), a exemplo de Freitas (1995) e Santos (2015). No caso da primeira, trata-se da dissertação intitulada Vestidas de Azul e Branco: um estudo sobre as representações de ex-normalistas (1920-1950), que teve como objetivo

[...] analisar as representações das ex-normalistas do Instituto de Educação Rui Barbosa - Escola Normal - acerca da formação profissional e do ingresso na carreira do magistério. Para realizar este estudo foram coletadas histórias de vida resumidas das ex-alunas que se formaram na instituição no período que compreende as décadas entre 20 e 50. Foram também analisados documentos oficiais. Buscou-se apreender, durante a análise, aspectos relacionados ao processo de ingresso no curso normal; à duração e estrutura do curso; à convivência no espaço escolar en- 
tre professores e alunas e ao início da carreira das ex-normalistas. o relato destas experiências acerca do cotidiano da formação da Escola Normal e do processo de ingresso na carreira permitiram conhecer não só as trajetórias individuais, como também as vivências coletivas no espaço escolar e a inserção no mercado de trabalho das professoras primárias de Aracaju, no período estudado (Freitas, 1995, resumo).

A partir do que está posto nesse resumo, verifica-se que Freitas (1995) examina a formação profissional das normalistas a partir de suas memórias. E, a partir de um exame interno, só foi possível identificar poucas referências à matemática e, em todos os casos, relacionadas a dificuldades de compreensão sobre os conteúdos matemáticos.

Já Santos (2015), com o título Uma investigação acerca dos saberes matemáticos na formação de normalistas em Sergipe (1890 - 1930), teve por objetivo "[...] analisar como foram organizados os saberes matemáticos (Arithmetica, Álgebra, Geometria e Desenho) para o Curso Normal do Instituto de Educação Rui Barbosa (IERB) no Estado de Sergipe, a partir da legislação publicada dos anos 1890 aos anos 30 do século XX" (Santos, 2015, p. 13).

Logo na introdução, Santos (2015) apresenta um entendimento para saberes matemáticos como "[...] aqueles conteúdos da matemática escolar presentes para o ensino no Curso Normal que foram estabelecidos na legislação sergipana" (Santos, 2015, p. 13). Constata-se, a partir desse entendimento, que a autora atrelou desde a definição do objetivo os saberes matemáticos a conteúdos e a disciplinas/matérias² Tal entendimento apresenta-se um pouco diferenciado em relação aos sistematizados por pesquisadores do GHEMAT, como Valente (2019), que indicam ser possível a partir de fontes, como as utilizadas por Santos (2015), caracterizar saberes a ensinar e saberes para ensinar como partes de um saber profissional do professor que ensina matemática.

Por conta disso, foi efetuado um exercício no sentido de dar visibilidade e ampliar o entendimento sobre saberes matemáticos a partir de fontes como: decretos, regulamentos e programas. O texto foi organizado em três tópicos: uma síntese sobre os saberes adotados como lentes, um exame de fontes em busca de indícios para caracterizar os saberes matemáticos e as considerações.

\section{Uma Definição para as Lentes: saber a ensinar e saber para ensinar como um saber profissional do professor que ensina matemática}

Um texto que permitiu inicialmente um repensar sobre o entendimento para saberes matemáticos foi o de Valente (2019) nominado como Programas de ensino e manuais escolares como fontes para estudos da constituição da matemática para ensinar. É possível, a partir do que está posto no título, adotar programas como uma fonte passível de identificar uma matemática para ensinar. Para isso, o autor trata sobre 
a matemática presente na formação de professores dos primeiros anos escolares, e a considera como parte de um "[...] conjunto de saberes profissionais do professor" (Valente, 2019, p. 52). E destaca que no processo de construção desse saber profissional, historicamente, foi sendo elaborada uma matemática para ensinar articulada a uma matemática a ensinar.

Vale destacar que Valente (2019, p. 52) afirma que matemática para ensinar "[...] revela-se como um saber profissional, uma matemática para o exercício da docência, uma ferramenta de trabalho do professor para ensinar matemática tendo em conta uma matemática a ensinar". E, no caso, o autor apresenta um caminho de como é possível mobilizar fontes como programas e manuais escolares para responder à pergunta: “[...] como estudar o processo de constituição da matemática para ensinar?" (Valente, 2019, p. 52). Ainda segundo o autor citado, para responder a tal indagação é preciso considerar traços históricos, vestígios, documentos do passado, que estão presentes na realidade atual, e interrogá-los para constituir fatos históricos.

Aqui vale ressaltar, mais uma vez, que, para a constituição desses fatos, foram tomados como fontes: decretos e programas referentes ao curso normal que funcionava no Instituto de Educação Rui Barbosa (IERB) no Estado de Sergipe, ainda que algumas dessas fontes já tivessem sido examinadas por Santos (2015) a partir de um entendimento de que os saberes matemáticos estavam atrelados somente aos conteúdos.

Porém, Valente (2019) amplia esse entendimento a partir de apropriações sistematizadas por pesquisadores suíços que defendem considerar dois tipos de saberes, conforme está apresentado a seguir.

\begin{abstract}
Um primeiro tipo um primeiro tipo caracterizado como 'saberes a ensinar'. Tais saberes têm referências nas disciplinas científicas e dizem respeito ao objeto de ensino da docência. De outra parte, há aos 'saberes para ensinar. Neste caso, tem-se um rol de saberes próprios do ofício docente, constituindo as suas ferramentas de trabalho na tarefa que têm os professores de formar pessoas. Desse modo ao considerar essas sistematizações sobre os saberes trabalhamos com a hipótese teórica que entende a matemática a ensinar como um saber advindo do campo matemático, reunindo uma gama de conteúdos que devem ser aprendidos por aqueles que estão no processo de formação (Valente, 2019, p. 53).
\end{abstract}

Valente (2019) defende, ainda, que tanto a constituição de uma matemática a ensinar, como a matemática para ensinar são resultantes de processos históricos, relacionados a cada época e as finalidades atribuídas a escola dentre vários outros determinantes.

A matemática para ensinar, também fruto do processo de elaboração histórica, não constitui um saber de cultura geral. Trata-se de um saber específico, de cultura profissional, próprio à formação do futuro docente. De outra parte, é preciso ressaltar, que a admissão da existência 
da matemática para ensinar não implica em sua autonomia. Sendo um saber específico, um saber do profissional da docência, uma ferramenta do ofício de ser professor, articula-se tal ferramenta com o objeto de ensino, a matemática a ensinar. Cabe somente à profissão docente a posse de um saber para ensinar, uma matemática para ensinar. Elaborada historicamente em articulação com a matemática a ensinar [...] será esse saber específico dos professores, um dos elementos que caracterizam a profissão docente (Valente, 2019, p. 54).

Constata-se, a partir do que está posto na citação, que o professor que ensina matemática deve ter em sua formação uma matemática para ensinar articulada à matemática a ensinar. E, para que seja possível, Valente (2019) chama atenção para aspectos relacionados aos conteúdos e ao uso do tempo escolar a partir desse entendimento em relação a uma matemática a ensinar.

Ainda segundo Valente (2019), os estudos que envolvem documentação oficial, a exemplo de programas, deverá atentar para a graduação do ensino. E a

[...] graduação está diretamente ligada à organização do saber para ensinar e enseja as finalidades do ensino, as metodologias, as concepções de ensino e de aprendizagem, o modo como deverá se dar a relação professor-aluno, o emprego do tempo escolar enfim, representa um saber organizado para ensinar, uma ferramenta do professor, uma matemática para ensinar (Valente, 2019, p. 57).

Os entendimentos pinçados de Valente (2019) são tomados como referente para examinar fontes em busca de uma caraterização do saber matemático das normalistas sergipanas.

\section{Saberes Matemáticos Propostos Para Normalistas Sergipanas: uma caracterização}

Para responder uma das indagações apresentadas incialmente sobre os saberes matemáticos presentes na formação das normalistas sergipanas no período de 1890 a 1930 foram utilizadas fontes ${ }^{3}$ como: decretos, regulamentos da instrução pública, leis, publicações do Diário Oficial e programas, referentes ao período de 1890 a 1930. Para a justificativa desse marco cronológico, foi utilizada a mesma argumentação apresentada por Santos (2015), o marco inicial de 1890 pela implementação do Decreto N. 30, de 15 de março de 1890, autorizado pelo Presidente Felisbello Firmo de Oliveira Freire, com a regulamentação para o Curso Normal. E o ano de 1930, como final, por ser um ano de propostas de mudanças para o ensino normal.

Quanto ao programa e horário, a simplificação daquele e a flexibilidade deste farão apelo às atividades infantis e darão maior autonomia didactica ao professor, pondo à sua disposição processos mais dynamicos, vitaes, effi- 
Saberes Matemáticos para a Formação de Normalistas em Sergipe (1890 - 1930)

cientes. Esses processos, em synthese, são os 'centros de interesse' e os 'projectos' dos systhemas Dewey e Decroly, tão em voga no velho e no novo mundo e em vários Estados do Brasil. São os característicos da 'Escola Nova', no qual é possível adaptar ao nosso ensino, por enquanto (Sergipe, 1930 apud Santos, 2015, p. 125).

As fontes examinadas nesse marco cronológico, com a ressalva que a tentativa apontada aqui é, à luz do que foi posto Valente (2019), buscam novas faces para os saberes matemáticos, para além da associação aos conteúdos matemáticos.

Uma primeira fonte examinada foi o Decreto N. 30, de 15 de março de 1890, aprovado por Felisbello Firmo de Oliveira Freire.

\begin{abstract}
As inúmeras reformas por que tem passado tão importante ramo do serviço público não têm produzido na prática resultado algum, de maneira a compensar os enormes sacrifícios feitos pelo Estado para manter o mesmo serviço. Nota-se um verdadeiro estado de desorganização, o que traz grande desproveito para o ensino público, e portanto, para as classes populares. Estado algum poderá encaminhar-se em busca da prosperidade sem que previamente cure com o mais vivo interesse do ensino popular, base principal do bem-estar das nações (Sergipe, 1890, p. 80).
\end{abstract}

Verifica-se que nos anos de 1890 havia, por parte dos gestores, uma preocupação com a organização do ensino em terras sergipanas. Em relação ao ensino normal no Decreto N. 30/1890, está posta uma orientação para o ensino público normal, ao orientar que "[...] aos aspirantes ao magistério primário as habilitações indispensáveis à sua profissão" (Sergipe, 1890, p. 122). E a primeira vez que aparece informações sobre saberes matemáticos é quando o legislador apresenta as temáticas gerais que deveriam ser abordadas em cada cadeira ${ }^{4}$, conforme está posto a seguir ${ }^{5}$.

Primeira cadeira: Lingua nacional: grammatica, redação, noções de literatura portuguesa e brasileira.

Segunda cadeira: Pedagogia e sua historia: methodologia logica, precedida de noções de psychologia experimental. Terceira cadeira: Noções de geographia e historia geraes; geografia e historia do Brazil, noções de cosmografia.

Quarta cadeira: Mathematicas elementares; arithmetica; noções de algebra até as equações do primeiro grao; geometria; applicações praticas.

Quinta cadeira: Sciencias physicas: noções de physica, chimica e mecânica physica; Sciencias naturaes: nocões de botânica, geologia (compreendendo noções de anatomia e physiologia humana). Geologia e hygiene (Sergipe, 1890, p. 122-123).

Constata-se, pelo que está posto nessa citação, que só na quarta cadeira é que aparecem as matemáticas e que, nesse caso, segundo Valente (2019), trata-se de um saber a ensinar já que tem referências às cadeiras/disciplinas. Além disso, no documento de 1890 há uma indi- 
cação de que as cadeiras de geometria e trigonometria, e de aritmética e álgebras deveriam ser reunidas sob a denominação de matemáticas elementares. Porém, ao examiná-lo, é possível identificar a seguinte informação a respeito.

O ensino normal será essencialmente prático baseado na experimentação e manipulação, de modo que os alunos possam considerar a matéria por todas as suas faces. Em qualquer estabelecimento do Estado, o ensino público será, quanto possível, intuitivo e prático, marchando sempre do simples para o composto, do particular para o geral, do concreto [sic] para o abstrato, do definido para o indefinido (Sergipe, 1890, p. 82).

Observa-se que, apesar de não ser diretamente relacionado à matemática a ensinar ou aos saberes a ensinar, essas são pistas presentes nos documentos oficiais, que fornecem indicativos de como, durante a formação, as normalistas deveriam trabalhar os saberes a ensinar. Esses são indicativos que podem constituir o saber para ensinar ou a matemática para ensinar.

O exame de documentos oficiais permite de pronto uma identificação da presença de saberes a ensinar ou de uma matemática a ensinar, e podem ser listados da seguinte forma:

- Regulamento de 1890 - Mathematicas elementares; Arithmetica; noções de álgebra até as equações do primeiro grao; geometria; applicações praticas.

- Lei No 366, de 1899 - Arithmetica e Desenho linear.

- Lei nº 398, de 1900 - Arithmetica e Desenho Linear.

- Regulamento de 1900 - Arithmetica e Álgebra.

- Regulamento de 1901 - Arithmetica.

- Regulamento de 1907 - Arithmetica.

No Decreto N. 563, de 12 de agosto de 1911, é proposto pelo então Presidente do Estado, José Rodrigues da Costa Doria, uma nova organização para o ensino normal, pois da forma que se encontrava até então, não atendia aos “[...] fins a que é destinado, não tendo a moderna pedagogia o desenvolvimento atualmente dado a esta matéria na sua relevante importância, nos métodos de ensino" (Sergipe, 1911, p. 13-14). Em 1911, o Curso Normal passou a ter duração de 4 anos, e reaparece a denominada Arithmetica e Elementos da Álgebra e Geometria. Ao que tudo indica, as orientações postas nesse decreto se adequam àquilo que Valente (2019) chama atenção em relação aos programas inovadores, ou, no caso, ao regulamento que busca alterar a organização do ensino normal.

Os programas inovadores podem ter em seus detalhamentos as orientações metodológicas para o ensino indicações de como o trabalho deve ser graduado. Tudo isso não está presente em manuais escolares assentados e normativas anteriores àquelas consideradas inovadoras; ou 
estando presente, as orientações serão diferentes daquela da daquelas da proposta inovadora. O caso extremo é de proibir adoção de obras didáticas consideradas ultrapassadas não condizentes com os novos programas (Valente, 2019, p. 56).

A partir do exame dos demais decretos, constata-se apenas uma indicação em relação ao saber a ensinar aqui entendido como matéria, disciplina ou cadeira.

- Decreto No 563, de 12 de agosto de 1911 Arithmetica, Álgebra e Desenho

- Decreto No 571, de 19 de outubro de 1912 Arithmetica e Desenho Linear

- Decreto N. 587, 09 de janeiro de 1915 Arithmetica, Desenho Linear e Noções práticas de Geometria Plana

- Decreto N. 630, de 24 de abril de 1916 Arithmetica, Noções de Álgebra, Geometria e Desenho.

- Decreto N. 724, de 20 de outubro de 1921 Arithmetica e Desenho

- Lei N 852, de 30 de outubro de 1923 Arithmetica, Álgebra e Geometria

- Decreto $N^{\circ}$ 867, de 11 de março de 1924 Arithmetica, Álgebra, Geometria e Desenho.

- Decreto $N^{\circ}$ 30, 11 de março de 1931 - Arithmetica, Desenho, Geometria plana e Noções de álgebra.

Verifica-se, a partir das informações elencadas, que essas rubricas podem ser associadas diretamente a uma matemática a ensinar. Além disso, Valente (2019), ao tratar sobre fontes como os programas oficiais, destaca que eles servem para fixar conteúdos e parametriza o tempo escolar.

Não está a bel prazer do professor demorar-se num tema, um assunto ou mesmo ministrar tão somente determinado conteúdo que de modo particular, individual o professor considera importante. Desde a época da escola graduada nos finais do século 19 os programas apontam quando em que época do curso tal qual conteúdo deverá ser ministrado, isto é, sedimentam um progresso que deve ser dado ao ensino graduação (Valente, 2019, p. 55).

Dito de outra forma, o professor não é livre para distribuir e abordar os conteúdos na ordem e no tempo que desejar, ou seja, o controle e a graduação, a sequência dos conteúdos fazia parte da formação do professor que ensinva matemática. E essa sequência não é apontada apenas com a denominação de Aritmética por exemplo, os tópicos são detalhados.

- Programa de $1917-1^{\circ}$ ano

Princípios fundamentais, relativos à grandeza e suas espécies, aos números inteiros; Numeração; Formação de unidades; Leitura e es- 
crita dos números; Operações fundamentais; Propriedades notáveis da adição e da subtracção; Multiplicação e divisão; Abreviações da multiplicação; O inverso das operações fundamentais; Redução à unidade; Igualdade e desigualdade; Quantidades positivas e negativas; Uso do parenthesis e do vínculo; Complemento dos números; Teoria dos números; Números primos e múltiplos; Determinação de todos os fatores primos de um número; Discriminação dos números primos na série natural dos números até um limite qualquer; Divisão por cancelamento; Teorema dos números múltiplos; Caracteres da divisibilidade, suas aplicações até 12; Decomposição dos números múltiplos em seus factores primos; Determinação de todos os divisores de um número; Prova destas operações; Busca do máximo comum divisor e do mínimo múltiplo comum de dois ou mais números; Fracções ordinárias; Princípios gerais, alterações, reducções e operações; Fracções mistas; Operações sobre as mesmas; Ideias gerais sobre as fracções decimais. Conversão de uma fracção ordinária em decimal e vice-versa; Operações; Dizima periódica e suas propriedades; Fracções geratrizes; Metrologia; Noção histórica dos sistema métrico decimal; Unidades principais; Nomenclatura dos múltiplos e submúltiplos; Abreviaturas do sistema; Operações sobre unidades métricas; Reducção de medidas antigas a modernas e vice-versa; Exercícios com problemas sobre cada uma das licções dadas.

- Programa de 1917 - 20 ano

Recapitulação do $1^{\circ}$ ano; Teoria dos números complexos; Conversões, reduções e operações; Provas das operações; Razões e proporções, suas propriedades. Regra de três simples, composta, juros simples, juro composto, divisão proporcional, sociedade comercial simples, sociedade commercial composta, desconto commercial, desconto racional, cambio, porcentagens e comissões; Exercícios e problemas acompanhando as licções.

- Programa de $1917-3^{\circ}$ ano

Teoria dos números; Números primos e múltiplos; Descriminação dos números primos pelo método do crivo; Decomposição dos números múltiplos em seus factores primos; Teorema da divisibilidade; Caracteres da divisibilidade; Determinação de todos os divisores de um número; Pares de divisores; Busca do máximo comum divisor e do mínimo múltiplo comum de dois ou mais números; Fracções ordinárias; Alterações, reducções, transformações e operações; Fracções decimais; Alterações, reducções, transformações e operações; Conversão das fracções decimais em ordinárias e vice-versa; Sistema métrico - Definições, idéias geraes; Resumo histórico do sistema métrico; Medidas antigas e modernas; Equivalência destas medidas; Coeficientes de redução; Operações sobre unidades métricas; Teoria dos números; Conversão de um número complexo em fracção da unidade principal e vice-versa; Reducções, operações e provas dos mesmos; Razões e proporções, suas propriedades; Regra de três simples e composta Juros, idem; Sociedade Comercial, idem Divisão proporcional Desconto, comercial e racional; Regra de falsa posição; Termo médio e prazo; Câmbio. 
Constata-se que a forma como os itens estão apresentados seguem uma sequência de uma matemática a ensinar. E segundo Morais, Bertini e Valente (2021) a sequência tem caráter histórico e muda em cada época pedagógica, mas nos programas examinados de 1919 e no de 1921 identifica-se uma preocupação com a sequência pois os conteúdos listados anteriormente passaram a receber uma indicação numérica, conforme está posto a seguir.

- Programas de ensino da matéria Arithmetica

$1^{\circ}$ Princípios fundamentais relativos à grandeza. Números inteiros. Numeração. Formação da unidade. Leitura e escripta dos números.

$2^{\circ}$ Operações fundamentais. O inverso destas operações. Abreviações da multiplicação.

$3^{\circ}$ Igualdade e desigualdade. Quantidades positivas e negativas. Uso do parentheses e do vínculo. Complemento dos números.

$4^{\circ}$ Decomposição dos números múltiplos em seus factores primos. Determinação de todas os divisores de um número. Pares de divisores.

$[\ldots]$

$2^{\circ}$ ano

Recapitulação do programma do $1^{\circ}$ anno

$15^{\circ}$ Numeração complexa. Reducção e operações sobre números complexos.

$16^{\circ}$ Razão e proporção.

$17^{\circ}$ Regra de três simples.

$18^{\circ}$ Regra de três composta.

$19^{\circ}$ Juros simples.

$20^{\circ}$ Juros composto.

$21^{\circ}$ Sociedade commercial simples.

$22^{\circ}$ Sociedade commercial composta.

$23^{\circ}$ Cambio sobre a Inglaterra e a França.

$24^{\circ}$ Cambio sobre Portugal e Estados Unidos.

$25^{\circ}$ Desconto comercial.

$26^{\circ}$ Desconto racional.

Defende-se aqui que a numeração funciona como um elemento da sequência, indica uma forma de orientar o professor. Dito de outra forma, os tópicos que deveriam ser trabalhados já estavam apresentados em programa anterior só que nesse último programa além da presença dos saberes a ensinar ou da matemática a ensinar e um indício de um saber para ensinar ou de uma matemática a ensinar a partir da sequência proposta.

Um destaque identificado nesse programa de 1917 para a Escola Normal - IERB é a indicação do compêndio Aritmética, de Antônio 
Trajano. Tal fato pode ser um indício do que foi apontado por Valente (2019).

\begin{abstract}
Os estudos que envolvem documentação oficial (os programas de ensino) [...] mostram-se importante para a caracterização da trajetória do saber profissional do professor que ensina matemática nos primeiros anos escolares, [...] A ênfase maior sobre o saber profissional do professor que ensina matemática para os primeiros anos escolares recai sobre a matemática para ensinar. No entanto é preciso ter em conta que se saber resultado do processo do histórico de elaboração está sempre em articulação com a matemática a ensinar, também fruto de processos históricos. Em níveis em mais amplos, isso quer dizer que as relações estabelecidas em cada tempo entre os campos disciplinares e a educação devem ocupar lugar nas análises sobre a produção dos saberes profissionais da docência (Valente, 2019, p. 61).
\end{abstract}

Constata-se que que a partir da documentação examinada, os indícios sobre os saberes para ensinar não são explícitos. Apesar de não ser explicito, é possível identificar, nos regulamentos, informações que são indícios claros do que deveria constituir a matemática a ensinar articulada a uma matemática para ensinar, conforme está apresentado a seguir.

A methodologia especial a cada matéria compete aos professores de cada uma das cadeiras correspondentes as do ensino primário e complementar. $\$ 2^{\circ} \mathrm{O}$ professor evitará os processos que sobrecarreguem a memória do alumno; o raciocínio deve ser a base de todo esforço. $\S 3^{\circ}$ Na organização dos programas de cada matéria, serão observados methodo e gradação semelhantes ao do ensino primário; o professor deverá sempre ter em vista que o objetivo do curso normal é o preparo para o ensino primário (Sergipe, 1916).

Tal orientação permanece em Regulamento de 1924.

A organização dos programas visava, principalmente, o
methodo objetivo, obedecendo os seguintes preceitos: $\S$
$1^{\circ}$ A methodologia especial a cada matéria compete aos
professores de cada uma das cadeiras correspondentes às
do ensino primário. $\S 2^{\circ} \mathrm{O}$ professor evitará os processos
que sobrecarreguem a memória do aluno; o raciocínio
deve ser a base de todo esforço. $\S 3^{\circ} \mathrm{Na}$ organização dos
programas de cada matéria serão observados methodos
e gradação semelhantes aos do ensino primário; o profes-
sor deverá ter sempre em vista que o objetivo do ensino
normal é o preparo para o ensino primário (Sergipe, 1924).

A orientação em relação ao saber para ensinar só muda a partir de 1931, quando aparece nos documentos oficiais a indicação explicita sobre o método intuitivo. "O ensino normal será orientado pelo methodo intuitivo, directo ou indirecto, e melhores processos que o ilustram: 
primeiro o objeto, a experiência, a demonstração; depois, a teoria, a definição”.

Aliado a isso, foi possível identificar que para a matemática a ensinar há uma possibilidade de identificação em relação à graduação, à sequência e aos métodos. Aspecto considerado, por Valente (2019), como importante para formação do saber profissional como ação e a sequência.

\section{Considerações Finais}

Quais são os saberes matemáticos presentes na formação de normalistas sergipanas no período de 1890 a 1930? Os saberes identificados podem ser classificados como um saber a ensinar ou como um saber para ensinar? Ou ainda, os saberes matemáticos identificados podem ser caracterizados como um saber profissional das normalistas? A partir dessas indagações postas no início do texto é possível filtrar expressões como saberes matemáticos, saber a ensinar, saberes para ensinar, saberes a matemáticos e saber profissional das normalistas que foram utilizados como lentes para examinar as fontes a partir de um refinamento teórico.

A partir de um exame a fontes como decretos e programas foi possível identificar saberes matemáticos localizados em rubricas como Aritmética, Álgebra e Geometria. Mas em um processo de refinamento e a luz de um entendimento teórico que defende a presença de uma matemática a ensinar e uma matemática para ensinar, foi possível identificar nessas rubricas um saber a ensinar ou, ainda, uma matemática a ensinar expressa seja pelo título maior da disciplina/matéria, ou pelo detalhamento de todos os tópicos elencados, nos programas examinados.

Depois de identificados elementos de uma matemática a ensinar foi necessário uma certa sutiliza para identificar a matemática para ensinar, que nem sempre é explícita. Verifica-se que o saber para ensinar, ou ainda, a matemática para ensinar está presente em orientações relativas ao como, por exemplo: o ensino normal deveria ser prático, baseado na experimentação e manipulação, o professor deveria evitar a memorização, o raciocínio deveria ser a base de todo esforço, intuitivo e prático. Tais orientações, sem dúvida nenhuma, conformariam a matemática para ensinar atrelada à matemática a ensinar.

Por fim, é possível afirmar que a combinação entre a matemática a ensinar e a matemática para ensinar identificados podem ser caracterizados como um saber profissional das normalistas sergipanas no período de 1890 a 1930. Com a ressalva de que o saber a ensinar, entendido como uma matemática a ensinar, aparece de forma explícita, e que o saber para ensinar/matemática para ensinar foi identificado de forma implícita, mas sem dúvida nenhuma, caracterizam um saber profissional das normalistas sergipanas.

Recebido em 15 de março de 2021 Aprovado em 19 de maio de 2021 


\section{Notas}

1 Evento realizado de 19 a 30 de outubro de 2020, no formato remoto e organizado por colegas da Universidade Federal do Rio Grande do Sul.

2 Vale esclarecer que para evitar anacronismos é utilizada neste texto a nomenclatura indicada nas fontes em relação ao uso das expressões cadeira, matéria e disciplina.

3 Aqui vale ressaltar que as fontes utilizadas estão disponibilizadas no Repositório de Conteúdo Digital da Universidade Federal de Santa Catarina - Repositório de Conteúdo Digital no endereço eletrônico https://repositorio.ufsc.br/ handle/123456789/98962.

4 Vale esclarecer, mais uma vez que para evitar anacronismos é utilizada neste texto a nomenclatura posta na fonte em relação a cadeira, matéria e disciplina.

5 Optou-se neste texto por manter a grafia utilizada em cada fonte examinada.

\section{Referências}

FREITAS. Ana Maria Gonçalves Bueno. Vestidas de Azul e Branco: um estudo sobre as representações de ex normalistas (1920-1950). 1995. 137 f. Dissertação (Mestrado) - Universidade Estadual de Campinas, Campinas, 1995.

MORAIS, Rosilda dos Santos; BERTINI, Luciane de Fátima; VALENTE, Wagner Rodrigues. A Matemática no ensino de frações: do século XIX a BNCC. São Paulo: Livraria da Física, 2021.

SANTOS, Ivanete Batista dos. Álgebra: exagerada ou sumida? 1998. Dissertação (Mestrado) - Universidade Federal de Sergipe, São Cristóvão, 1998.

SANTOS, Valdeci Josefa de Jesus. Uma Investigação Acerca dos Saberes Matemáticos na Formação de Normalista em Sergipe. 2015. 127 f. Dissertação (Mestrado) - Universidade Federal de Sergipe, São Cristóvão, 2015.

SERGIPE. Colecção de Leis e Decretos de 1890. Decreto No 30, de 15 de março de 1890. Aracaju: Typ. d' O Estado de Sergipe, 1890. Disponível em http://repositorio.ufsc.br/handle/123456789/103579. Acesso em: 12 de março de 2021.

SERGIPE. Colecção de Leis e Decretos de 1911. Decreto N. 563, de 12 de agosto de 1911. Aracaju: Typ. d' O Estado de Sergipe, 1911. Disponível em https://repositorio.ufsc.br/xmlui/handle/123456789/124888. Acesso em 12 de março de 2021.

SERGIPE. Colecção de Leis e Decretos de 1916. Decreto N. 630, de 24 de abril de 1916. Aracaju: Typ. d' O Estado de Sergipe, 1916. Disponível em https://repositorio.ufsc.br/handle/123456789/104705. Acesso em 12 de março de 2021.

SERGIPE. Compilação de Leis e Decretos do Estado de Sergipe. Lei N. 867, de 11 de Março de 1924. Aracaju: Typ. d' O Estado de Sergipe, 1924. Disponível em https://repositorio.ufsc.br/handle/123456789/104709. Acesso em 12 de março de 2021.

SERGIPE. Justificação dos projectos da nova regulamentação do ensino público primário e normal (continuação). Diário Oficial do Estado de Sergipe, Aracaju (SE), Quinta-feira, 18 de Dez. de 1930.

VALENTE, Wagner Rodrigues. Processos de Investigação Histórica da Constituição do Saber Profissional do Professor que Ensina Matemática. Revista Acta Scientiae, v. 20, p. 377-385, 2018. 
Saberes Matemáticos para a Formação de Normalistas em Sergipe (1890 - 1930)

VALENTE, Wagner Rodrigues. Programas de Ensino e Manuais Escolares como Fontes para Estudo da Constituição da Matemática para Ensinar. Alexandria Revista de Educação em Ciências e Tecnologia, v. 12, p. 1-63, 2019.

VALENTE, Wagner Rodrigues; BERTINI, Luciane de Fátima; MORAIS, Rosilda dos Santos. Novos Aportes Teóricos - metodológicos os sobre saberes profissionais na formação de professores que ensinam matemática. Revista Acta Scientiae, v. 19, p. 224-235, 2017.

Ivanete Batista dos Santos é doutora em Educação, História, Política, Sociedade pela Pontifícia Universidade Católica de São Paulo (2006) e atualmente professora associada do Departamento de Matemática e do Programa de Pós-graduação em Ensino de Ciências e Matemática da Universidade Federal de Sergipe. Pesquisadora vinculada aos grupos de pesquisa GHEMATBrasil e ao NIEPHMAT, e investiga sobre temáticas relacionadas a história da educação matemática, a educação matemática e a trajetória de formação e atuação de professores que ensinam matemática.

ORCID: https://orcid.org/0000-0001-6984-3661

E-mail: ivanetebs@uol.com.br

Editor-responsável: Luís Armando Gandin

Este é um artigo de acesso aberto distribuído sob os termos de uma Licença Creative Commons Atribuição 4.0 Internacional. Disponível em: <http:// creativecommons.org/licenses/by/4.0>. 